Rev. Psicol. (Arequipa. Univ. Catól. San Pablo) / Año 2019 / Vol 9 / N 3 / pp. 59-71

ISSN 2306-0565 versión impresa / ISSN 2311-7397 versión on line

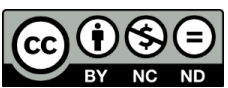

Esta obra está bajo una Licencia Creative Commons

Atribución 4.o Internacional (BY-NC-ND)

\title{
HACIA DESCRIPCIONES NÍTIDAS \\ DE LA CULTURA ORGANIZACIONAL
}

\author{
TOWARD SHARP DESCRIPTIONS \\ OF ORGANIZATIONAL CULTURE
}

\author{
Federico R. León', Oswaldo Morales², Oswaldo Otoya ${ }^{2}$, Antonio Romero², \\ Ángela de la Cruz y Fiorella Sarria \\ 1. Universidad San Ignacio de Loyola, Lima, Perú \\ 2. Universidad ESAN, Lima, Perú
}

\begin{abstract}
Resumen
El Marco de Valores en Competencia es el modelo mejor estudiado de cultura organizacional. Su instrumento de evaluación solicita al informante distribuir 100 puntos entre opciones de respuesta representativas de los cuatro tipos de cultura del marco. Un sesgo en las respuestas ocurre cuando el informante, aplicando el menor esfuerzo o temiendo represalias, distribuye los 100 puntos en montos aproximadamente iguales. Este artículo presenta análisis de datos provenientes de una empresa pública peruana que produjeron descripciones más válidas de la cultura organizacional cuando se convirtió los puntajes a is y os, dependiendo de si el puntaje era o no el mayor de los cuatro. Un estudio que además evaluó liderazgo y bienestar emocional en una empresa privada generó resultados equivalentes.
\end{abstract}

Palabras clave: cultura organizacional, técnica de medición, validez.

\begin{abstract}
The Competing Values Framework is the best studied model of organizational culture. The Assessment of Organizational Culture Instrument asks of the respondent the distribution of 100 points among response options representing the four cultures of the framework. A response bias occurs when the informant, applying least effort or afraid of negative consequences, distributes the 100
\end{abstract}


points approximately equally among the four categories. This article presents analyses of data from a public organization in Peru which produced more valid descriptions of organizational culture when the scores were converted into is and os, depending on whether or not a score was the highest one. A study that in addition evaluated leadership and emotional well-being in a private organization generated equivalent results.

Key words: organizational culture, measurement technique, validity.

\section{Hacia descripciones nítidas de la cultura organizacional}

El volumen 64 del Annual Review of Psychology trae una excelente evaluación del estado del arte en el área de la cultura organizacional (Schneider, Ehrhart, \& Macey, 2013). El concepto se originó en la antropología y desde un principio tuvo foco en lo colectivo. Su principal novedad estuvo en la demostración de cómo las creencias, ideologías, rituales, y mitos ayudan a entender a las organizaciones. En los 1980s emergieron gurús del tema que lograron gran impacto populary también apareció el estudio riguroso de la cultura organizacional, en dos perspectivas. Una, la comparativa, explora los atributos de las organizaciones que diferencian a las más de las menos eficaces. La otra trata de entender cómo los miembros de la organización desarrollan significados y llegan a compartir ciertos supuestos básicos. En esos procesos se ha distinguido la cultura de las sub-culturas, así como de las franjas ambiguas, y se ha identificado niveles, tales como los de los artefactos visibles, los valores abrazados, y los supuestos subyacentes (Schein, 2010). Los principales temas de investigación abarcan el rol del liderazgo, que moldea la cultura cuando los valores y comportamientos del líder llevan al éxito; los vínculos existentes entre cultura nacional, por un lado, y cultura organizacional y tipo de liderazgo, por otro; y la relación entre cultura organizacional y desempeño de la organización (Sackman, 2011), donde destaca el Marco de Valores en Competencia o MVC (Competing Values Framework; Quinn \& Rohrbaugh, 1983; Cameron, Quinn, DeGraff, \&Thakor, 2006). El MVC fue desarrollado en respuesta a la necesidad de un marco teórico de aplicación general que permitiera comparar organizaciones y entender el contexto en el que ciertos valores llevan al éxito. Pese a su antigüedad, el MVC continúa siendo el eje referencial que mejor describe y explica la cultura organizacional en relación al desempeño organizacional. Recientemente, Hartnell, Ou, y Kinicki (2011), en un meta-análisis de 84 estudios que comprendían 94 organizaciones de diversos países, hallaron que los tipos de cultura del MVC se asocian diferentemente a los criterios de desempeño y, pese a que no todos los aspectos de su estructura interna recibieron apoyo empírico, el MVC tiene un importante potencial de utilidad. El MVC es una tipología de organizaciones basada en el cruce ortogonal de una dimensión de estabilidad y control versus flexibilidad y discrecióny una dimensión de orientación 
hacia adentro e integración de las personas versus orientación hacia afuera de la organización y diferenciación de las personas. El cruce origina cuatro tipos de organización: Cooperación, Creación, Competición, y Control.

Los autores del presente artículo creen que una de las áreas donde el MVC necesita perfeccionamiento es la de medición de la cultura, pues el Organizational Culture Assessment Instrument (OCAI) que se usa en el diagnóstico de las cuatro culturas presenta problemas. Una versión preliminar del OCAI definía cuatro tópicos y solicitaba a los informantes valorar cuatro opciones de respuesta para cada uno, correspondientes a los cuatro tipos de cultura del MVC, aplicando una escala Likert de siete puntos (Quinn \& Spreitzer, 1991). Cameron y Quinn (1999) ampliaron los tópicos a seis ítems (rasgo dominante, liderazgo, gestión del personal, énfasis estratégico, factor unificador, y criterio de éxito) y pidieron a los informantes distribuir 100 puntos entre las cuatro opciones de respuesta de cada ítem. Esto se realiza en dos etapas; primero en relación a la organización como es ahora y, luego, a la que le gustaría al informante que fuera. Las estructuras psicométrica y factorial del OCAI han sido estudiadas en los más diversos contextos con resultados positivos (v.g., Choi, Seo, Scott, \& Martin, 2010; Pierce, 2004). Sin embargo, mientras que algunos investigadores emplean la distribución de 100 puntos (v.g., Gálvez Albarracín \& García Pérez de
Lema; 2011; Martínez Ramos, Ollivier Fierro, \& Escobedo Cisneros, 2007), otros continúan usando escalas Likert (Borjas de Xena, 2010; Nummelin, 2007). En cualquier caso, el OCAI no ha sido innovado después del $2006 \mathrm{y}$, así, continúa enfrentando problemas. El mayor consiste en la tendencia del personal a ofrecer respuestas ambiguas, generalmente dadas para salir del paso o, peor aún, dadas con el propósito de evitar opiniones claras por temor a represalias. Después de los escándalos internacionales de los Wikileaks y el espionaje digital norteamericano, el personal de las empresas sospecha que hasta las encuestas on-line vienen con truco y permiten su identificación pese a la usual promesa de anonimato y confidencialidad adelantada por los investigadores o consultores. La manera de no comprometerse es ofrecer respuestas ambiguas. Por ejemplo, distribuir los 100 puntos pedidos en el OCAI en cuatro partes más o menos iguales o asignar puntajes Likert con escasa variación. El principal problema con este tipo de sesgo será que los resultados del estudio emergerán con un alto grado de ambigüedad y pondrán a los consultores en el trance de no poder ofrecer un diagnóstico nítido de la cultura organizacional y a los investigadores en el de quedarse con una hipótesis de sesgo no demostrada. Los estudios presentados en este artículo evaluaron una estrategia original de puntuación en el OCAI, usando como criterio evaluativo su impacto sobre la nitidez de los resultados y la validez del diagnóstico. 


\section{Estudio 1}

\section{Contexto y participantes}

Este estudio se realizó como parte de una consultoría a una organización pública reguladora de la actividad empresarial de un sector de la economía peruana (ORG). Establecida en los 1990s, la ORG ha ganado premios internacionales de excelencia y es considerada un modelo de empresa en el sector público. La totalidad de su personal fue invitado a responder a una encuesta on-line que produjo respuestas de 271 del medio millar de empleados, la mayoría ingenieros. La pérdida de casos se explica por el plazo muy corto para responder - 48 horas - que se dio al personal a causa de las presiones de tiempo ejercidas sobre el estudio.

\section{Instrumento y procedimiento}

Se empleó una traducción castellana de los seis ítems del OCAI. Una tarea del informante fue la de describir a la ORG como un todo; la otra, describir su propia área funcional. En ambos casos se solicitó la distribución de 100 puntos entre las cuatro opciones para cada ítem. Las respuestas para cada ítem fueron convertidas luego a is (para el tipo de cultura indicada como la prevaleciente según el puntaje asignado, aunque la diferencia fuese mínima) y os (para los tipos de cultura con menores puntajes). Los casos donde se producía un empate exacto en el primer puesto fueron descartados del análisis.

\section{Resultados}

Siguiendo el modelo de Cameron y Quinn (1999), mientras más parecida sea la diagramación de la cultura organizacional a un cuadrado con su centro coincidiendo con el cruce de los ejes vertical y horizontal, más ambiguo será el diagnóstico de una cultura, a no ser que la cultura sea realmente equilibrada. Pero ni siquiera una de las docenas de organizaciones representadas en el libro de Cameron et al. (2006) presentó una diagramación tan parecida a un cuadrado al centro de la figura como la resultante de la distribución de 100 puntos ofrecida por el personal de la ORG del presente estudio en referencia a su área de trabajo (Figura 1).

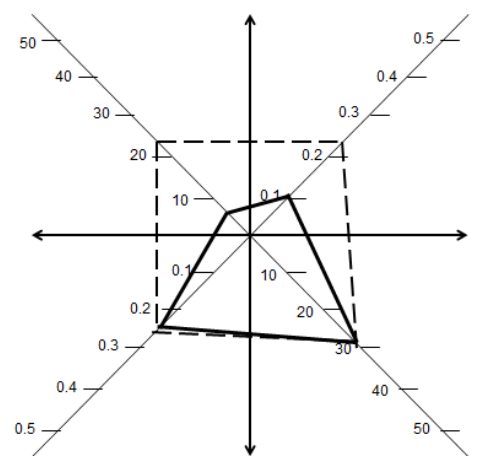

Figura 1. Diagramación de resultados de cultura para la ORG según 100 puntos distribuidos (línea punteada) y conversión a is y os (línea sólida).

Nota: Las dos modalidades de puntuación representadas en las escalas diagonales - se aplican a cada cuadrante. Las culturas representadas son Cooperación (arriba, izquierda), Creación (arriba, derecha), Control (abajo, izquierda), y Competición (abajo, derecha). 
Lo que está representado allí es una cultura ideal en el sentido de equilibrar las cuatro culturas. En contraste, la conversión a is y os (línea continua) dio lugar a una forma desequilibrada donde la cultura de Cooperación se redujo a un mínimo y la de Creación se le aproximó.

La Figura 2 describe de manera más convencional el promedio de puntajes por ítem del OCAI -también en referencia a la propia área de trabajo- contrastando los resultados obtenidos a partir de la distribución de 100 puntos entre las opciones de respuesta y a partir de su transformación a 1s y os. Los resultados para la ORG como un todo fueron parecidos y no se reportan aquí. Se puede notar que, en todos los casos, la variación de puntajes es mayor cuando se usa los is y os.
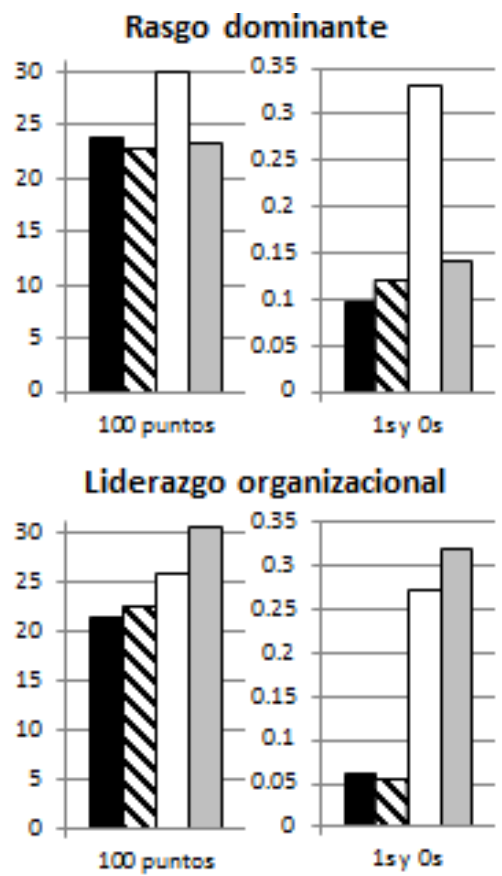

Gestión de personal
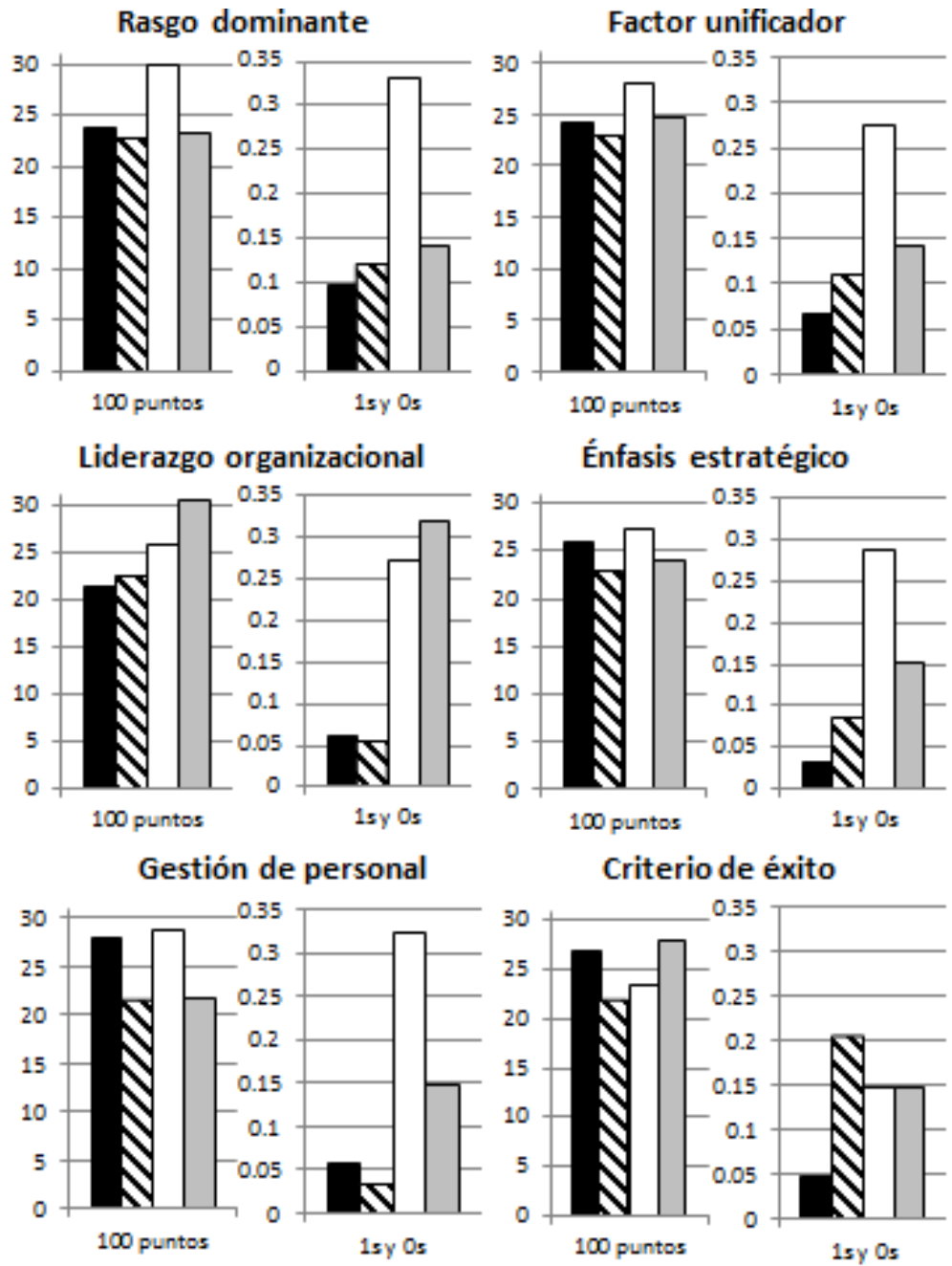

100 puntos

1sy Os

\section{Criterio de éxito}

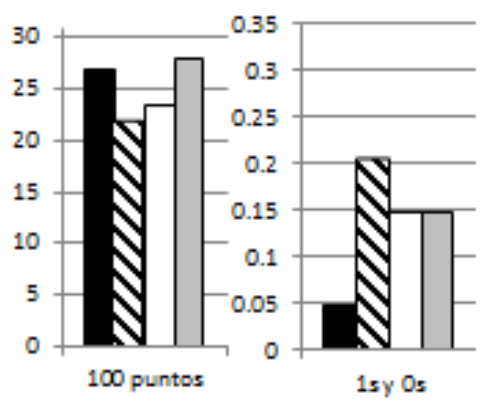

Figura 2. Valores para cada cultura en cada ítem según tipo de puntuación 
Exceptuando Criterio de éxito y Liderazgo organizacional, en todos los ítems Competición emergió claramente diferenciado como el valor prevalente. En el otro extremo, Cooperación redujo sustancialmente su prevalencia en cada uno de los ítems. Similar fue el caso de Creación, aunque emergió como el primer valor respecto a Criterio de éxito. Control mantuvo su primer lugar en Liderazgo organizacional y, en general, se colocó como el segundo en importancia.

La presentación final de resultados al cliente solo consideró aquellos basados en la conversión de puntajes a is y os. La cultura organizacional fue descrita por los consultores como una guiada por un criterio de profesionalismo y orientada a resultados competitivos y un grado importante de control que ha puesto poco énfasis en la cooperación entre áreas funcionales y en la creación de un clima de cooperación. Por consiguiente, se recomendó el fortalecimiento del área de recursos humanos y el desarrollo de líneas de carrera. El área de recursos humanos es una parte menor de la administrativa, la cual, a su vez, es considerada una función de segundo orden en la ORG. Allí recursos humanos se encarga básicamente de tareas rutinarias y quien está a cargo no es hombre, ni ingeniero, ni gerente; es decir, carece totalmente de poder dentro de la ORG.

La alta dirección de la organización reconoció como válida la descripción y la explicó tomando en cuenta que, en sus primeros años, el liderazgo organizacional orientó los esfuerzos del personal a tareas de supervisión y fiscalización que eran valoradas en sí mismas pero después fueron fijadas metas en términos de impactos en el sector que pusieron mayor énfasis aún en resultados cuantificables. De allí el fuerte énfasis actual en competición.

\section{Discusión}

La declaración de la gerencia representa una validación del reporte, es decir, de los resultados obtenidos con los is y os. Si los consultores hubiesen basado su informe en los resultados de la técnica de distribución de 100 puntos y hubiesen concluido que había tanta cooperación como competición en la empresa habrían causado pasmo en la ORG y habrían perdido credibilidad. En cambio, el diagnóstico de una cultura de competición largamente dominante en la ORG presentado por los consultores no fue cuestionado por ninguno de los 17 participantes de nivel gerencial que acudieron al taller de discusión de la evidencia. Sin embargo, siendo este un estudio de casos con metodología cualitativa, queda abierto a cuestionamientos metodológicos y requiere una replicación que incluya criterios de validez de mayor rigor.

\section{Estudio 2}

\section{Contexto y participantes}

El Estudio 2 es parte menor de una tesis de licenciatura en psicología sobre la relación entre mecanismos de influencia social ejercidos por los jefes y bienestar emocional de los subordinados. Se realizó 
en una organización privada de servicios dedicada a vender seguros y dar asistencia y acompañamiento al turista en viajes nacionales e internacionales. De origen argentino, la oficina de Lima opera desde hace 20 años. La totalidad de su personal $(\mathrm{N}=149)$ fue invitado individualmente a responder a una encuesta cara-a-cara, obteniéndose respuestas de 110 empleados. La principal razón para la pérdida de casos fueque los momentos de recolección de datos (de 9 am a $5 \mathrm{pm}$ ) no coincidieron con los laborales del tercio del personal de operaciones en el turno de madrugada.

\section{Instrumentos y procedimientos}

Se empleó la traducción castellana del OCAI con referencia al área funcional del informante. Participaron en el estudio solo los subordinados. Al igual que en el Estudio 1, se solicitó la distribución de 100 puntos entre las cuatro opciones de respuesta, pero, dado el alto número de empates observados, las respuestas para cada ítem fueron convertidas luego a 35 (para el tipo de cultura indicada como la prevaleciente según el puntaje asignado en casos sin empate), zs (para el empate de dos tipos de cultura en el primer lugar), 1s (si hay empate de tres), y o.5 (si hay empate de cuatro). Los restantes puntajes fueron convertidos a os. Se puede interpretar la alta tasa de empates como un resultado de la recolección de datos cara-a-cara, donde la promesa de anonimato es menos creíble por el informante.

Además, se pidió a los jefes $(\mathrm{N}=13)$ que calificaran mediante una escala Likert la medida en que usaban con su personal varios mecanismos de influencia derivados de la conceptualización de French y Raven (1959), que identifica seis modalidades: información, recompensa, coerción, legitimidad, experticia, y referencia. Algunas de estas categorías fueron subdivididas en subcategorías siguiendo a Raven, Schwartzwald y Koslowsky (1998) y Raven (2008). Ellos definieron formas personales e impersonales de recompensa y coerción, y diferenciaron posición, reciprocidad, y equidad en el poder legítimo. Nuestro análisis diferenció mecanismos duros de influencia (reforzador impersonal, coerción, legitimidad por posición) y mecanismos blandos (reforzador personal, información, experticia, referencia, y legitimidad por equidad y reciprocidad).

Finalmente, se pidió a todos los subordinados que indicaran la frecuencia de cada uno de los 6o estados emocionales del Positive and Negative Affect Schedule ampliado o PANAS-X (Watson \& Clark, 1999) experimentados en el curso del último mes.

\section{Resultados}

Una vez descartados los casos donde la suma de puntajes distribuidos del OCAI excedía 100 o era menor que 10o, el tamaño de muestra se redujo a 86 casos. La consistencia interna del OCAI se evaluó separadamente para los puntajes referidos a cada tipo de cultura. Dado el bajo número de ítems (6), los alfas fueron moderados: cooperación $=.60$, creación $=.51$, control $=.70$, y competición $=.42$. Los paneles A y D de la Figura 3 se refieren a los puntajes 
correspondientes a los departamentos de administración y recursos humanos combinados en un solo grupo $(\mathrm{N}=16)$, los paneles B y E a los del departamento de comercialización $(\mathrm{N}=30)$, y los paneles $\mathrm{C}$ y $\mathrm{F}$ a los del departamento de operaciones $(\mathrm{N}=40)$. En la hilera alta están los puntajes distribuidos entre las cuatro culturas y en la hilera baja aparecen los resultados de su conversión a 3s, 2s, 1s, $0.5 \mathrm{~s}$, y os. Se puede notar fácilmente que, mientras el grupo de administración y recursos humanos mantiene el diagrama virtualmente inalterado, los otros dos grupos exhiben cambios importantes. Así, la diferenciación de los tres grupos resultó mínima en función de los puntajes distribuidos, pero muy nítida en el caso de los puntajes convertidos (D, E, y $\mathrm{F})$, que diferencian con claridad a administración/RRHH de comercialización tanto como de operaciones.
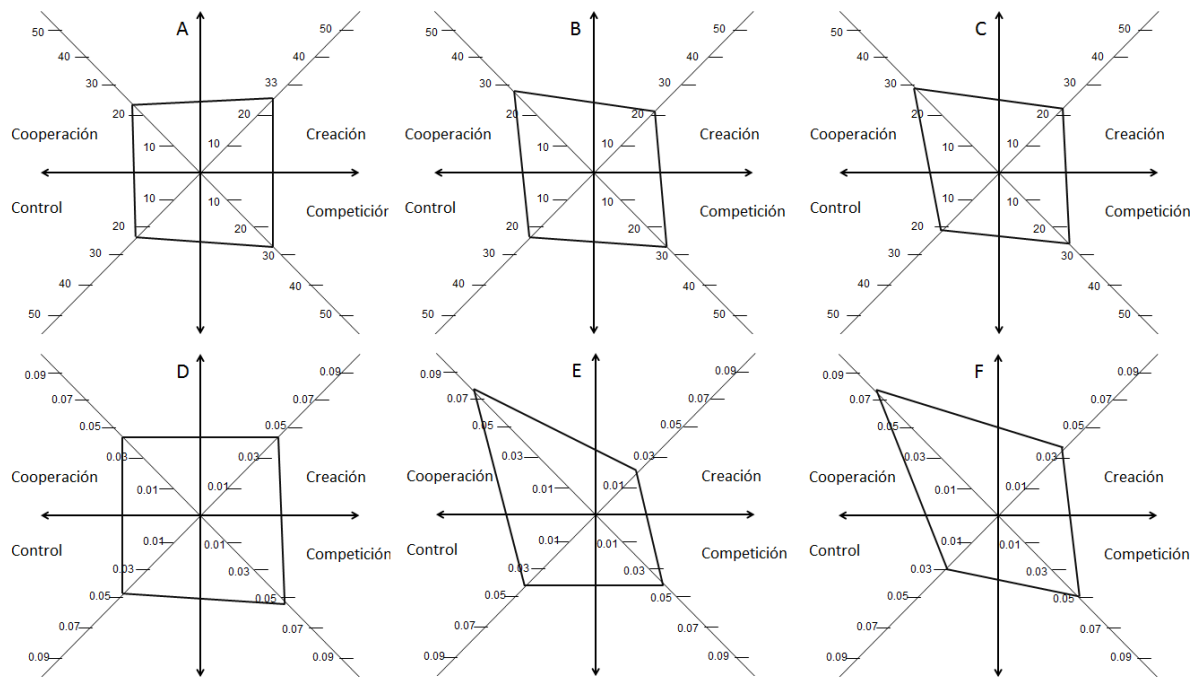

Figura 3. Diagramación de resultados de cultura para administración/RRHH (paneles A y D), comercialización (paneles B y E), y operaciones (paneles C y F), la hilera de arriba según distribución de 100 puntos y la hilera de abajo según conversión de los puntajes a 3s, 2s, 1s, 0.5s, y os

Los puntajes de influencia fueron bastante confiables para fines de investigación $(\alpha=.71$ para mecanismos duros $y .75$ para mecanismos blandos). La Figura 4 deja notar que, en paralelo con la diferenciación conseguida merced a la conversión de puntajes de cultura, administración y $\mathrm{RRHH}(\mathrm{N}=4$ gerentes $y$ jefes) se diferencia espacialmente de comercialización ( $\mathrm{N}=6$ ) y operaciones $(\mathrm{N}=3)$ en el uso de mecanismos de influencia duros y blandos al formar los últimos grupos un conjunto distante del primero. Los resultados sugieren que en administración/RRHH se ejerce más liderazgo de los dos tipos que en las otras gerencias. 


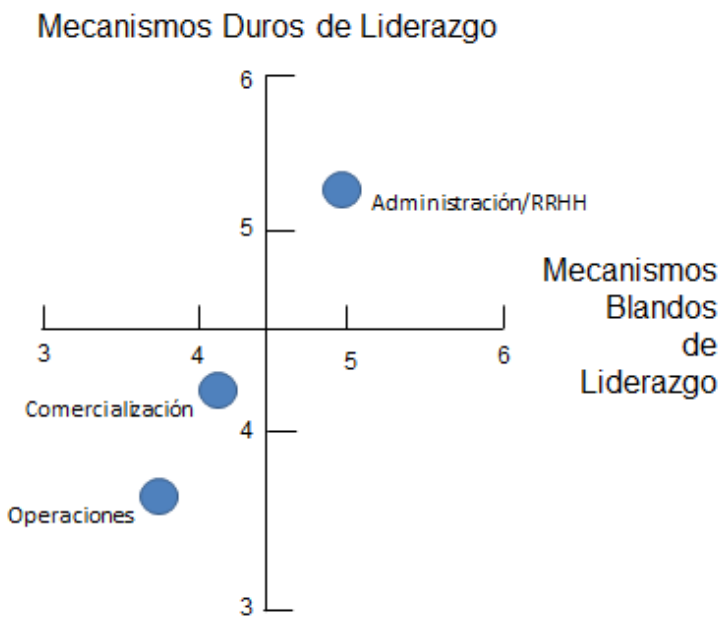

Figura 4. Promedios de liderazgo duro y liderazgo blando para cada gerencia

Luego de eliminar los casos de sujetos que no habían respondido a todos los ítems del PANAS-X, el número de casos se redujo a 104. Un análisis de componentes principales con rotación varimax en busca de los dos primeros componentes confirmó los supuestos del PANAS, pues los ejes resultantes fueron claramente definibles como emociones negativas (Factor 1) y emociones positivas (Factor 2). Consecuentemente, construimos una escala de emociones negativas con los 24 ítems con cargas en el Factor 1 superiores a .40 y una de emociones positivas con los 18 ítems con cargas igualmente fuertes en el Factor 2. Los $\alpha$ de Cronbach fueron, respectivamente, .90 y .89. Los promedios de emociones positivas en administración/RRHH $(\mathrm{N}=11)$ y el grupo combinado de comercialización y operaciones $(\mathrm{N}=74)$ fueron, respectivamente, 39.36 y 46.08 ; es decir, el segundo grupo presentó más emociones positivas. La Tabla 1 presenta los niveles de significación estadística para las diversas variables; las mujeres presentaron significativamente más emociones positivas que los hombres. Los promedios de emociones negativas - 45.09 y 42.95no difirieron significativamente entre los dos grupos $(\mathrm{F}=0.267, p<.61)$. 
Tabla 1. Modelo Linear General para la Suma de Emociones Positivas según el Grupo de Pertenencia, Controlando por Nivel Jerárquico, Sexo, y Tiempo en la Empresa del Informante

\begin{tabular}{|lccccc|}
\hline \multicolumn{1}{|c}{ Origen } & Suma de Cuadrados & $\begin{array}{c}\text { Grados } \\
\text { de Libertad }\end{array}$ & $\begin{array}{c}\text { Media } \\
\text { Cuadrática }\end{array}$ & F & P \\
\hline Modelo corregido & 1034.41 & 4 & 258.60 & 2.57 & .044 \\
Intersección & 1730.08 & 1 & 1730.08 & 17.20 & .000 \\
Nivel jerárquico & 4.00 & 1 & 4.00 & 0.04 & .843 \\
Sexo & 421.18 & 1 & 421.18 & 4.19 & .044 \\
Tiempo en la empresa & 219.58 & 1 & 219.58 & 2.18 & .143 \\
Grupo & 347.13 & 1 & 347.13 & 3.45 & .067 \\
Error & 8047.78 & 80 & 101.00 & & \\
Total & 182831.00 & 85 & & & \\
Total corregido & 9082.19 & 84 & & & \\
\hline
\end{tabular}

Nota: Grupo es una variable dicotómica (administración/RRHH versus comercialización/operaciones). $R_{2}=.114 . ~ R 2$ corregido $=.070$.

\section{Discusión}

Según la medición de la cultura organizacional basada en la distribución de 100 puntos, administración/RRHH no se diferenciaría de comercialización u operaciones. La conversión de los puntajes, en cambio, produjo una clara diferenciación. Las evaluaciones del liderazgo fueron consistentes con esta diferenciación al mostrar que el liderazgo se ejercía de manera distinta en administración/RRHH que en comercialización y operaciones, aunque los pequeños números de casos impidieron evaluar la consistencia estadística. Sin embargo, respecto al bienestar emocional fue posible evaluar rigurosamente la consistencia de los hallazgos. Tal como se esperaría de una cultura tendiente a la cooperación o cultura tipo Clan, los niveles de bienestar emocional por el lado positivo fueron mayores en comercialización/operaciones que en administración/ RRHH y la diferencia bordeó la significación estadística $(p<.07)$. Es probable que con un mayor número de casos en administración/RRHH se hubiera conseguido significación de mantenerse la tendencia.

La impresión que dejan los hallazgos es que la cultura de la empresa está fuertemente orientada a la cooperación, pero una parte pequeña y secundaria de ella (administración/RRHH) no está comprendida dentro de ese espíritu y presenta mayor necesidad de supervisión y menor felicidad. Esta conclusión, sin embargo, hubiese escapado al diagnóstico de haberse basado el estudio en la distribución de 100 puntos. 


\section{Discusión General}

Evidentemente, los estudios 1 y 2 deben ser considerados solo los primeros pasos de varios requeridos para lograr un OCAI capaz de producir descripciones más nítidas y válidas de la cultura organizacional. Habiendo sido la conversión a is y os una solución de emergencia en el curso de una consultoría que fue conveniente replicar constructivamente en la segunda investigación, los estudios estuvieron limitados a una simulación estadística cuando el ideal hubiese sido un tratamiento experimental. Futuros estudios deben comparar los resultados de solicitar la distribución de 100 puntos a un grupo del personal seleccionado aleatoriamente y la asignación de is y os (o un esquema parecido) a un grupo equivalente, es decir, seleccionado al azar del mismo universo. El verse el informante forzado a optar podría traer consecuencias no necesariamente idénticas a las conseguidas aquí mediante la simulación estadística. Pero la congruencia de nuestro informe sobre cultura con la visión de los cuadros gerenciales de la ORG del
Estudio 1 y con los estilos de liderazgo y bienestar emocional en el Estudio 2 sugiere que los hallazgos deben tomarse en cuenta. Por consiguiente, vale la pena ir reflexionando sobre sus implicancias prácticas.

Una es la duda que levantan sobre la validez de las evaluaciones de clima organizacional, que son mucho más frecuentes que las de cultura organizacional en el Perú. Considérese el siguiente ítem de un cuestionario ampliamente utilizado por la firma líder del mercado peruano de estudios de clima, "Los jefes me mantienen informado acerca de temas y cambios importantes", a ser respondido mediante una escala Likert. Muy poca validez tendrán las respuestas si el personal que responde a un cuestionario de clima organizacional con preguntas de este tipo lo hace de la manera sesgada como lo hizo el de los dos estudios presentados aquí al distribuir 100 puntos entre las opciones de respuesta. La recomendación que sigue, entonces, es la de continuar haciendo esfuerzos por despejar las dudas tanto en el área de la cultura organizacional como en la del clima organizacional. 


\section{Referencias}

Borjas de Xena, L. (2010). Cultura y liderazgo en una empresa de servicios venezolana. Anales de la Universidad Metropolitana, 10, 139-162.

Cameron, K. S., \& Quinn, R. E. (1999). An introduction to changing organizational culture. Diagnosing and Changing Organizational Culture: based on the Competing Values Framework. San Francisco, CA: Jossey-Bass.

Cameron, K. S., Quinn, R. E., DeGraff, J., \&Thakor, A. V. (2006). Diagnosing and Changing Organizational Culture: based on the Competing Values Framework. Northampton, MA: Elgar.

Choi, Y. S., Seo, M., Scott, D., \& Martin, J. J. (2010). Validation of the Organizational Culture Assessment Instrument: An application of the Korean version. Journal of Sport Management, 24, 169-189.

French, J. R. P. Jr., \& Raven, B. H. (1959). The bases of social power. En D. Cartwright (Ed.), Studies in social power (pp. 1-14). Ann Arbor, MI: Institute for Social Research.

Gálvez, E. J., \& García, D. (2011). Cultura organizacional y rendimiento de las Mipymes de mediana y alta tecnología: Un estudio empírico en Cali, Colombia. Cuadernos de Administración y Organización, 24, 125-145.

Hartnell, C. A., Yi Ou, A., \& Kinicki, A. (2011). Organizational culture and organizational effectiveness: A meta-analytic investigation of the Competing Values Framework's theoretical suppositions. Journal of Applied Psychology, 96, 677-694.

Martínez, P. J., Ollivier, J. O., \& Escobedo, J. C. (2013). Relación entre la cultura organizacional y el desempeño de la organización: Un estudio en empresas maquiladoras de la ciudad de Chihuahua. Revista de Estudios en Contaduría, Administración e Informática, 2, 77-100.

Nummelin, J. (2007). Measuring organizational culture in construction sector Finnish sample. Journal of Construction \& Management, 23, 215-225.

Pierce, J. G. (2010). Is the organizational culture of the United States Army congruent with the professional development of its senior level officer corps? Recuperado de http://www.Strategic Studies Institute.army.mil el 22 de octubre de 2013.

Quinn, R. E., \& Rohrbaugh, J. (1983). A spatial model of effectiveness criteria: Towards a 
competing values approach to organizational analysis. Management Science, 29, 363-377.

Quinn, R. E., \& Spreitzer, G. M. (1991). The psychometrics of the Competing Values Culture Instrument and an analysis of the impact of organizational culture on the quality of life. En R. W. Woodman \& W. A. Pasmore (Eds), Research in organizational change and development, Vol. 5. Greenwich, CON: JAI Press.

Raven, B. H. (2008). The bases of power and the power/interaction model of interpersonal influence. Analyses of Social Issues and Public Policy, 8, 1-22.

Raven, B. H., Schwartzwald, J., \& Koslowsky, M. (1998). Conceptualizing and measuring a power/interaction model of interpersonal influence. Journal of Applied Social Psychology, 28, 307-332.

Schein, E. H. (2010). Organizational culture and leadership. Vol. 2. New York: Wiley.

Schneider, B., Ehrhart, M. G., \& Macey, W. H. (2013). Organizational climate and culture. Annual Review of Psychology, 64, 361-388.

Watson, D., \& Clark, L. A. (1999). The PANAS-X: Manual for the Positive and Negative Affect Schedule, Expanded Form. Obtenido del University of Iowa Institutional Repository.

Recibido: 22 de abril de 2019

Aceptado: 24 de setiembre de 2019 